\title{
Presence of katG gene in resistant Mycobacterium tuberculosis
}

\author{
M Jaber, A Rattan, R Kumar
}

\begin{abstract}
It has been reported recently that isoniazid resistant strains of Mycobacterium tuberculosis have lost the katG gene which encodes the catalase-peroxidase enzyme. A 35 mer oligonucleotide probe specific for the katG gene of $M$ tuberculosis, $3^{\prime}$ end-labelled with digoxigenin, was constructed and hybridised with DNA extracted from 26 clinical isolates of $M$ tuberculosis under high stringency conditions. Twenty two of these isolates were resistant to $0.2 \mu \mathrm{g} / \mathrm{ml}$ isoniazid and 20 to $1.0 \mu \mathrm{g} / \mathrm{ml}$ isoniazid. Semiquantitative detection of catalase did not show any discrimination between isoniazid sensitive and resistant strains. The katG gene was present in all clinical strains of $M$ tuberculosis. Therefore, complete deletion of the katG gene does not seem to be the mechanism of isoniazid resistance in $M$ tuberculosis strains isolated from patients in India.

(F Clin Pathol 1996;49:945-947)
\end{abstract}

Keywords: Mycobacterium tuberculosis, isoniazid, catalase-peroxidase enzyme, katG gene, isoniazid resistance.

Isonictotinic acid hydrazide or isoniazid was first described in 1912, though its powerful activity against Mycobacterium tuberculosis was not recognised until 1951. The minimal inhibitory concentration (MIC) of isoniazid is extremely low $(0.02-0.05 \mu \mathrm{g} / \mathrm{ml})$ and this undoubtedly contributes to its efficacy. ${ }^{1}$ Shortly after the introduction of isoniazid, it was noted that some highly resistant clinical isolates lacked the haem containing enzyme catalase-peroxidase (hydroperoxidase I) and were often avirulent in the guinea pig model. ${ }^{2}$ It is now known that the toxicity of isoniazid results from a peroxidation reaction that is catalysed by the enzyme catalase-peroxidase, which is encoded by the katG gene. ${ }^{3}$ Compelling evidence for a link between catalaseperoxidase and resistance to isoniazid came from the finding that some highly resistant isolates of $M$ tuberculosis lacked the katG gene. ${ }^{4}$

The aim of the present study was to investigate the feasibility of rapid detection of isoniazid resistance by detecting katG gene deletion in DNA extracted from clinical isolates of $M$ tuberculosis.

\section{Methods \\ BACTERIAL ISOLATES}

Sputum samples from 257 consecutive patients were processed for the isolation of mycobacteria. Decontaminated and concentrated samples were inoculated onto two slopes of Lowenstein-Jensen medium. All isolates were identified to species level using conventional biochemical tests. ${ }^{5}$ Catalase was detected using a semiquantitative method. ${ }^{6}$ Drug susceptibility to isoniazid was measured using the Middlebrook agar proportionate method. ${ }^{5}$

\section{EXTRACTION OF DNA FROM $M$ TUBERCULOSIS}

$M$ tuberculosis DNA was extracted from clinical isolates using the guanidinium hydrochloride lysis method. ${ }^{7}$ Briefly, 60-120 mg mycobacterial culture was transferred from a LowensteinJensen slant to a screw capped glass tube containing $1 \mathrm{ml}$ lysis buffer (6 M guanidinium hydrochloride; $50 \mathrm{mM}$ EDTA; $1 \mathrm{mM}$ 2-mercaptoethanol; $0.05 \%$ Tween 80 ) and three glass beads, vortexed to suspend the bacterial cells and transferred to an Eppendorf tube which was incubated at $4^{\circ} \mathrm{C}$ for 30 minutes and then immediately transferred to a water bath set at $75^{\circ} \mathrm{C}$ for 30 minutes. Debris was removed by centrifugation at $10000 \times g$ at $4^{\circ} \mathrm{C}$ for 10 minutes and the supernatant was transferred into another Eppendorf tube. DNA was precipitated in the supernatant with 0.5 volume of ice cold ethanol and kept at $-20^{\circ} \mathrm{C}$ for one hour. After centrifugation at $12000 \times g$ for 15 minutes, the DNA pellet was redissolved in $0.8 \mathrm{ml}$ lysis buffer without Tween 80 . DNA was extracted first with phenol/chloroform $(1 / 1, v / v)$ and then with chloroform/isoamyl alcohol $(24 / 1, \mathrm{v} / \mathrm{v}) .5 \mathrm{M} \mathrm{NaCl}$ was added to a final concentration of $0.3 \mathrm{M}$. DNA was precipitated with 2 volumes ethanol, kept for 20 minutes or overnight at $-20^{\circ} \mathrm{C}$. After centrifuging at $12000 \times g$ for 15 minutes. DNA was washed with $1 \mathrm{ml} 70 \%$ ice cold ethanol, the DNA pellet was dried and dissolved in TE buffer ( $\mathrm{pH} 8.0)(60-120 \mu \mathrm{l})$. The yield of DNA extracted from $60-120 \mathrm{mg}$ bacteria \\ Department of
Microbiology, All India \\ Sciences, Ansari \\ 20 July 1996
}


ranged from 84 to $278 \mu \mathrm{g}$ and the purity ranged from 1.84 to 2 (average 1.9).

To determine the specificity of the probe, DNA was also extracted from Escherichia coli, Klebsiella pneumoniae, Pseudomonas aeruginosa, Staphylococcus aureus, Streptococcus pneumoniae, $S$ pyogenes, Salmonella typhi, S typhimurium, and Bacillus stearothermophilus from our laboratory stock cultures.

\section{SELECTION AND SYNTHESIS OF THE} OLIGONUCLEOTIDE PROBE

The probe was selected by obtaining the nucleotide sequences of the katG gene of $E$ coli, $B$ stearothermophilus, $S$ typhimurium, and $M$ tuberculosis from European Molecular Biology Laboratories (EMBL), Heidelberg, and aligning them. A 35 mer sequence, 5'-CGCT GCGGGTGGATCCGATCTATGAGCGGA TCACG-3' was selected as being specific for the $M$ tuberculosis katG gene and did not have significant homology with katG sequences from other bacteria. The oligonucleotide probe was then synthesised (Bangalore Genie) and labelled using the digoxigenin oligonucleotide tailing kit (Boehringer Mannheim).

\section{HYBRIDISATION WITH katG PROBE}

Hybridisation was carried out at $68^{\circ} \mathrm{C}$ for six hours in $5 \times$ SSC on nylon membranes. The membrane was washed twice for five minutes each at $68^{\circ} \mathrm{C}$ with $2 \times \mathrm{SSC}, 0.1 \%$ SDS followed by two washings with $0.1 \times$ SSC, $0.1 \%$ SDS. The hybridised probe was visualised using nitroblue tetrazolium and $\mathrm{X}$-phosphate as described by the manufacturer (Boehringer Mannheim).

\section{Results}

Of the 257 samples examined, 56 were smear positive and 29 were both smear and culture positive. Twenty six isolates were identified as $M$ tuberculosis. The remaining three were $M$ scrofulaceum in two cases and $M$ fortutium in one.

Only four of the 26 isolates of $M$ tuberculosis were susceptible to $0.2 \mu \mathrm{g} / \mathrm{ml}$ isoniazid and six to $1 \mu \mathrm{g} / \mathrm{ml}$ isoniazid; 20 were resistant. In the semiquantitative test for the presence of catalase, the height of bubbles produced by all isolates was less than $20 \mathrm{~mm}$ and therefore all were negative. ${ }^{6}$ However, this test did not differentiate between isoniazid sensitive and isoniazid resistant isolates (fig 1).

The probe, under high stringency conditions, hybridised only with DNA extracted from $M$ tuberculosis but did not differentiate between isoniazid susceptible and isoniazid resistant strains as it hybridised to all 26 isolates of $M$ tuberculosis (fig 2).

\section{Discussion}

Several hypotheses have been proposed to explain the relation between catalaseperoxidase activity and isoniazid resistance in $M$ tuberculosis. Zhang et al provided evidence that the lack of catalase expression in $M$ tuberculosis was important in some isoniazid resist-

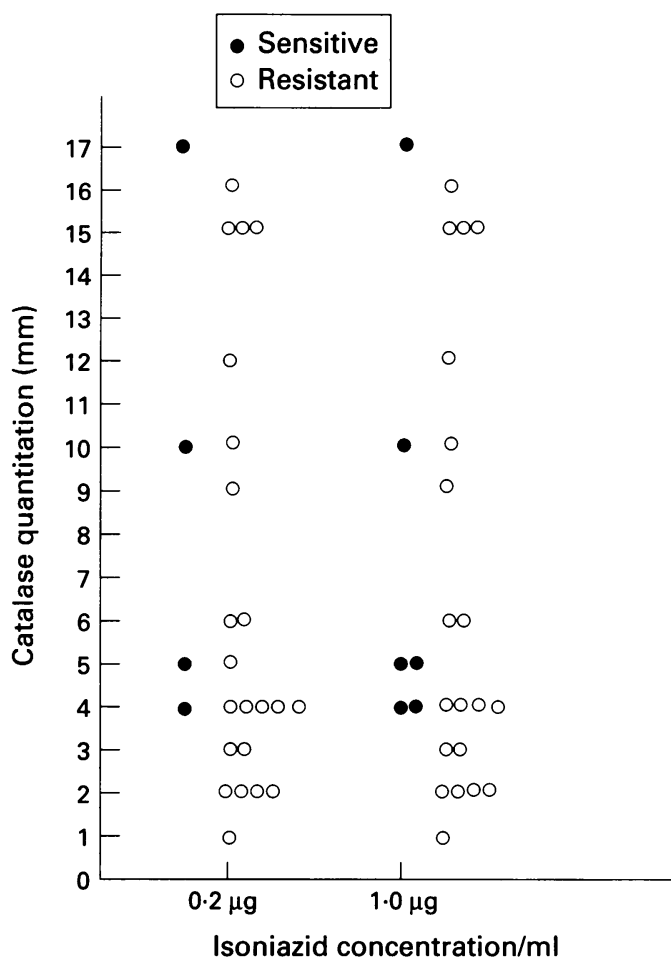

Figure 1 Isoniazid susceptible and resistant strains of $\mathrm{M}$ tuberculosis (at $0.2 \mu \mathrm{g} / \mathrm{ml}$ and $1 \mu \mathrm{g} / \mathrm{ml}$ ) and the height of bubbles produced in the semiquantitative catalase test.

ant strains. They showed that two of three high level resistant $M$ tuberculosis strains (MIC $>50$ $\mu \mathrm{g} / \mathrm{ml}$ ) lacked the katG gene and concluded that in a subset of isoniazid resistant strains, the lack of catalase activity was due to the complete loss of the katG gene.

It has been suggested that isoniazid interacts with catalase-peroxidase and is converted by the peroxidase activity into a toxic derivative which acts at a second, as yet unknown, site. Most bacteria contain two catalases, one of which is a broad spectrum enzyme endowed with peroxidase activity (hydroperoxidase I). The second catalase (hydroperoxidase II), which by preferentially removing $\mathrm{H}_{2} \mathrm{O}_{2}$, limits the ability of catalase-peroxidase to oxidize isoniazid. As $M$ tuberculosis lacks the latter activity, its catalase-peroxidase enzyme can convert isoniazid to the lethal form without competition for the electron acceptor. The deletion of katG gene encoding the catalase-peroxidase enzyme would therefore make the strain resistant to isoniazid. $^{8}$

Convincing evidence for the central role of katG gene in conferring susceptibility in $M$ tuberculosis was provided when isoniazid resistant isolates of $M$ tuberculosis could be transformed with a plasmid vector carrying the functional katG gene. Expression of katG restored full drug susceptibility in isolates initially resistant to concentrations ranging from 3.2 to $>50 \mu \mathrm{g} / \mathrm{ml}$ isoniazid. ${ }^{9}$ However, Stoeckle et al, ${ }^{10}$ using PCR, found that 31 $(76 \%)$ of the 41 isoniazid resistant strains in New York city contained katG sequences. Altamirano et $a l^{11}$ amplified a 237 base pair sequence of the katG gene of one isoniazid susceptible and nine isoniazid resistant isolates by PCR. Amplification was observed in the isoniazid susceptible as well as in eight of the 
nine isoniazid resistant isolates. DNA sequencing showed that eight of the nine isolates had a point mutation, deletion or insertion of one to three bases only.

Our probe for the $M$ tuberculosis katG gene hybridised with all 26 smear and culture positive clinical isolates of $M$ tuberculosis, indicating that the katG gene was not deleted completely in any of the 20 isoniazid resistant strains. These three studies taken together suggest that complete deletion of the katG gene does not seem to be the underlying mechanism of isoniazid resistance. Our probe, though specific for $M$ tuberculosis, cannot be used as a marker for isoniazid susceptibility.

The authors wish to acknowledge the support and advice provided by Professor P N Tandon, Professor of Neurosurgery, Katoch, Deputy Director, JALMA, and Dr Bimal K Das, Katoch, Deputy Director, JALMA, and Dr Bimal K Das, Department of Microbiology, AIIMS, during the course of this is gratefully acknowledged.

1 Cole ST. Mycobacterium tuberculosis: drug resistance mechanisms. Trends Microbiol 1994;2:411-20.
2 Middlebrook G. Isoniazid resistance and catalase activity of tubercle bacilli. American Review of Tuberculosis 1954;69: 471-2.

3 Zhang Y, Heym B, Allen B, Young D, Cole S. The catalaseperoxidase gene and isoniazid resistance of $M$. tuberculosis. Nature 1992;358:591-3.

4 Zhang Y. Genetic basis of isoniazid resistance of $M$. tuberculosis. Proceedings of the 9th Forum in Microbiology. Amsterdam: Elsevier Science 1994:143-9.

5 Kent PT, Kubica GP. Public health mycobacteriology. A guide for the level III laboratory. Atlanta: Centers for Disease Control, 1985.

6 Baron EJ, Peterson LR, Finegold SM. Mycobacteria. In Bailey Scott's Diagnostic microbiology.9th edn. St Louis: Balley Scott's Diagnos

7 Jaber M, Rattan A, Verma A, Tyagi J, Kumar R. A simple method of DNA extraction from Mycobacterium tuberculosis. Tuber Lung Dis 1995;76:578-81.

8 Heym B, Zhang Y, Poulet S, Young D, Cole ST. Characterization of katG gene encoding a catalase-peroxidase required for the isoniazid susceptibility of $M$. tuberculosis. $\mathcal{F}$ Bacteriol 1993;175:4255-9.

9 Zhang Y, Garbe T, Young D. Transformation with katG restored isoniazid sensitivity in $M$. tuberculosis isolates resistant to a range of drug concentrations. Mol Microbiol 1993;8:521-4.

10 Stoeckle MY, Guan L, Riegler N, Weitzman I, Kreiswirth B, Kornblum J, et al. Catalase-peroxidase gene sequences in INH susceptible and resistant strains of $M$. tuberculosis from New York city. $\mathcal{F}$ Infect $D$ is 1993;16:1063-5.

11 Altamirano $M$, Marostenmaki J, Wong A, FitzGerald $M$, Black WA, Smith JA. Mutations in the catalase-peroxidase gene from INH resistant $M$. tuberculosis isolates. 7 Infect Dis 1994;19:1162-5.

\title{
Benefits and limitations of pathology databases to cancer registries
}

\author{
D H Brewster, J Crichton, J C Harvey, G Dawson, E R Nairn
}

Scottish Cancer Registry, Information and Statistics Division, Trinity Park House, South Trinity Road, Edinburgh EH5 3SQ

D H Brewster

J Crichton

J C Harvey

G Dawson

\section{Department of}

Pathology, Crosshouse Hospital, Kilmarnock, Ayrshire KA2 0BE

E R Nairn

Correspondence to:

Dr D H Brewster.

Accepted for publication 12 August 1996

\begin{abstract}
In order to assess the benefits and limitations of pathology databases to cancer registries, computerised pathology records of malignant neoplasms diagnosed during 1992 were obtained for a defined area of Scotland for which pathology data were not routinely being used for cancer registration. Apparently 'missed' cancer registrations were identified by computerised probability matching with cancer registration records and their eligibility for registration was determined by reference to medical records, or when these were unavailable, by reference to the text of the original pathology report in conjunction with the local Community Health Index (to establish residency at the time of diagnosis). Misclassifications of site or incidence year were not regarded as 'missed' cases. Of 218 apparently 'missed' cancer registrations identified from computerised pathology records, $133(5.7 \%$ of the revised total number of registrations for the study area in 1992) should have been registered. A further 14 cases were already registered but with misclassified site, morphology and/or behaviour codes. Ascertain-
\end{abstract}

ment of cases by the Scottish Cancer Registration Scheme seems to be high for most sites. Pathology databases represent a useful additional source of cases but the fact that 71 apparently 'missed' cases were found to be ineligible for registration as independent primary malignant neoplasms suggests that unverified computerised pathology data should not be used uncritically nor independently for cancer registration purposes.

(f Clin Pathol 1996;49:947-949)

Keywords: neoplasms, pathology, registries.

High quality cancer registration data are an essential prerequisite of any rational cancer control strategy. ${ }^{1}$ As about $81 \%$ of registrations in Scotland are verified histologically (unpublished data, 1994), pathology data represent a potentially excellent source of case ascertainment and offer the prospect of increasing the validity of diagnoses and the accuracy of information recorded about morphology.

In order to assess the benefits and limitations of computerised pathology data to a cancer registry, we studied a defined area of Scotland served by a single pathology laboratory whose data were not already being used for cancer 